\title{
The Perceptions of Mexican-American Men as Fathers
}

\author{
Jeffrey Shears \\ Rich Furman \\ Nalini Junko Negi
}

\begin{abstract}
This qualitative study explores the lived experience of self-identified Mexican men as fathers. The sample consists of 47 biological fathers of children residing in Denver, Colorado, all whom are participating in the Early Head Start Research and Evaluation Project. The data suggests that these fathers engaged in traditionally conceptualized fathering roles. These men expressed the importance of being there, teaching, meeting the child's needs, being a role model, offering emotional support, and giving affection and love. The fathers reported taking more responsibility, decreasing substance use, and limiting their leisure activities as a result of becoming a parent. The results suggest that, fathering in and of itself, may create resiliency and may have powerful positive influences on the lives of fathers.
\end{abstract}

Keywords: Latino men, fathers, masculinity, fathering roles

\section{INTRODUCTION}

Empirical research has found a positive relationship between a father's involvement and an infant's early physical and psychosocial development (Shears \& Robinson, 2005; Lamb, 2002; Palcovitz, 2002; Federal Interagency Forum on Child and Family Statistics, 1998a; 1998b). Additional studies suggest that fathers contribute differently to infant developmental outcomes than do mothers (Horn, 1999; Lamb, 1997; Yogman, 1981; Lamb \& Lamb, 1976). While this link has been established, much of it has been through quantitative analysis that has merely identified the key variable and outcomes involved. While important, more information regarding the lived experiences of fathers is needed. By understanding the lived experiences of fathers themselves, family practitioners will be able to better understand how men construct their identities as fathers and will be able to more sufficiently provide services to them.

Several scholars have noted that much of what we know about a father's parenting attitudes and experiences was collected from the mother's reports (Shears,

\footnotetext{
Jeffrey Shears, Ph.D. is associate professor and BSW coordinator, Department of Social Work, College of Health and Human Service, University of North Carolina at Charlotte, Charlotte, NC 28223. Rich Furman, MSW, Ph.D. is associate professor and director of the Social Work Program at the University of Washington, Tacoma, WA 98402-3100. Nalini Negi, MSW is assistant professor, School of Social Work, University of Maryland at Baltimore, Baltimore, MD 20850.
}

Copyright $^{\oplus} 2007$ Advances in Social Work Vol. 8 No. 2 (Fall 2007) 338-352. Indiana University School of Social Work. 
Summers, Boller, \& Barclay-McLaughlin, 2006; Cherlin \& Griffith, 1998; Tanfer \& Mott, 1997). As social service and other providers seek to support positive outcomes for children and families, the experience of fathers via-a-vis their parenting are essential to understand. Given this importance, one might hypothesize that fathering attitudes and experiences might differ across race and ethnicity. However, much of what we know about fathering is from Western middle-class, well-educated families; research is needed regarding the perceptions of fatherhood with ethnicallydiverse populations (Palcovitz, 2002). Too often, models of development and parenting derived from white middle-class families and men are constructed as socially normative and are viewed as the benchmark through which to view the experiences of other men. However, such over-generalizations can lead to misunderstandings at best, and stereotyping at worst (Furman \& Collins, 2005).

As the Latino population in the United State continues to grow, social service practitioners and researchers are realizing that more must be done to understand the lived experiences of Latinos (Furman, \& Negi, 2007). This is particularly true for Latino men. Too often, cultural variables, such as machismo and paternalismo, are misunderstood by the social service community and others who work with Latinos. The experience of Latino men is often viewed through a lens of pathology, rather than by understanding their unique lived experiences through important Latino values.

This exploratory study seeks to join a growing body of research on the lived experience of Latinos, in particular, Mexican-Americans. This study will specifically explore attitudes, experiences, and perceptions of self-identified MexicanAmerican fathers of children residing in the Denver, Colorado metropolitan area. The study represents a component of Early Head Start children and families, both of which shall be explored in a later section of this paper.

\section{RESEARCH ON FATHERS}

Much of what we know of men's experiences as fathers is derived from research in Anglo communities (Shears, 2007; Jarret, Roy, \& Burton, 2002; Palcovitz, 2002; Toth $\& \mathrm{Xu}, 1999)$. The focus of much of this research has been on examining the differences between fathering and mothering (Shears \& Robinson, 2005; Hernandez \& Brandon, 2002; Kokkinaki \& Kugiumutzakis, 2000; Bumpass, Raley, \& Sweet, 1995), the effects of the father-infant relationship (Storey, Walsh, Quinton, \& WynneEdwards, 2000; Bader, 1995), exploring the experiences of fathers (Shears, Summers, Boller, \& Barclay-McLaughlin, 2006; Housaain, Fields, Pickens, Malphurs, \& Del Valle, 1997; Parke, 1995), and how men learn to father (Snarey, 1993; Cowan \& Cowan, 1987; Sagi, 1982). These studies also suggest that fathers are more likely to be involved in social activities, play, physical interactions, unusual, and unpredictable play. Because of the types of interactions and activities fathers participate in, they may interact differently with their children than mothers do. These differences in interactions suggest that fathers offer something unique to early infant development. In addition, the research on father-infant relationships suggests that fathers are emotionally connected to their infants, even to the point of having hormonal changes around the birth of their child (Storey, Walsh, Quinton, \&Wynne-Edwards, 2000). 
Another area of focus has explored how fathering is in a state of transition, as more fathers are embracing both traditional and contemporary roles. Traditional roles embrace activities, such as provider, protector, role model, disciplinarian, entertainer/socializer, and teacher, while the more contemporary roles might consist of caregiver, as partner with the child's mother, and as a source of affection and emotional support (Shears, Summers, Boller, \& Barclay-McLaughlin, 2006). A number of studies have identified differences in these roles with ethnic minority fathers (Shears, 2007; Jarett, Roy, \& Burton, 2002; Mincy, 2002; Toth \& Xu, 1999). These findings further strengthen the need for understanding how fathering experiences may be different among ethnic minorities.

\section{Hispanic Fathers}

Studies suggest that Hispanic families are more family-oriented than Anglo families, and particularly that Mexican-American families report more participation in large family networks (Sabogal, Marin, \& Otero-Sabogal, 1987; Vega, 1990). A few studies have examined how Hispanic fathers' attitudes differ from Anglo fathers. Sanchez (1997) found that Mexican-origin families are egalitarian, in that fathers take an equal role in household responsibilities, including child rearing. Shears (2007) found that Hispanic fathers reported higher levels of socialization activities with their children than did Anglo fathers. Toth and Xu (1999) suggest that Hispanic fathers tend to reinforce the norms of family closeness and expect their children to show respect for and conform to authority. Consequently, it is suggested that they monitor and supervise their children more closely than Anglo fathers. A study by Hofferth (2003) found that Hispanic-American fathers mirror Anglo fathers in the number of hours they reported spending with their child during the week, while also reporting higher levels of caring for their child than Anglo fathers. The study concluded that Hispanic fathers displayed higher levels of warmth and were more permissive in their parenting styles. Although these studies highlight the positive aspects of Hispanic fathers, a number of these studies compared them to Anglo fathers. There is a need to expand our understanding of Hispanic fathers and to understand their experiences in fathering within their cultural context. As a result, the current study explores Mexican fathers as a single group, without comparing them to others.

\section{METHOD}

\section{Early Head Start Research and Evaluation Project}

\section{Early Head Start (EHS)}

Designed to enhance a child's cognitive, socio-emotional, and behavioral development, as well as the parental capacity to engage in educational support activity, EHS includes intensive services that begin before a child is born and supports the family throughout the early years of a child's life from ages 0 to 3 . A national team of researchers and federally-funded agencies collaborated with EHS programs to evaluate the program's implementation and outcomes at 17 research sites across the United States. Following a random assignment design, a sample of nearly 3,000 children and mothers were recruited while the children were 12 months of age or younger. The mothers completed a series of interviews, including a baseline 
enrollment interview, a parent services interview at 6, 15, and 26 months following random assignment, and an exit interview. Data collection for the ongoing Early Head Start national evaluation focused on the primary caregiver-the female parent in more than $95 \%$ of the cases-as the key respondent. Although the responses from interviews with mothers yielded a wealth of data on fathers and father-figures, researchers also included an in-depth set of studies that focused specifically on fathers as the primary respondents. These studies helped to fill existing gaps in the body of knowledge by adding a further dimension to our understanding of how fathers, in the greater context of their family and the Early Head Start program, influence infant and toddler development.

The father study included measures parallel to the study of mothers. Such measures included: 1) measures of family resources and supports, 2) knowledge of child development, 3) parent characteristics, such as education and depression, and 4) videotaped interactions of father and child. Data for fathers who agreed to participate in the study were collected when their respective children were 24 months old. Further, an embedded qualitative study involving audiotaped, open-ended questions was incorporated into the study and interspersed throughout the quantitative interview. Thus, this study is part of a larger mixed-method research project, as reported in Boller, Cabrera, Raikes, Pan, Bradley, Shears, \& Roggman (2006). Data for this report were taken from interviews with men who were verified as being the father or father-figure of the EHS child at 24 months.

\section{Participants}

This study includes 47 fathers who completed a qualitative interview around their child's 24-month birthday. The sample consisted of English, Spanish, or bi-lingual speaking men who self-identified as Mexican-American and who were more than 19 years old. These men were reported by the mother to be the biological father or father-figure of a young child participating in two Early Head Start programs in Denver, Colorado, which were currently involved in a research and evaluation project. Mothers who were enrolled in Early Head Start initially identified the participants in this study as the father/father-figure of their child when the child was two years of age. As a result, these men were the father or father-figure of at least one child who was around two years old. Because of the requirements of enrollment in Early Head Start, the families and children are low income. However, the men associated with these families were not necessarily low income.

\section{The Interview}

The interviews include a core set of qualitative questions designed to assist in the generation of new hypotheses about Mexican-American fathers and their involvement in their children's lives. This study consists of several open-ended, qualitative questions to explore the experiences and perceptions of Mexican-American men on their fathering in low-income families. The study was designed not from a particular qualitative tradition, but from a generic qualitative perspective (Caelli, Ray, $\&$ Mill, 2003) in which the researchers sought to inductively approach the experience of Hispanic men. 
Thematic analysis was conducted to uncover themes based upon the data. The first author read each of the interviews and, with the assistance of a Hispanic male qualitative researcher, developed initial codes and categories. Subsequent readings lead to the development of more refined themes. The first author and the research assistant discussed the coding schemes that each developed and, through a process of negotiation and consensus building, developed themes that both believed accurately reflected the data. This type of peer-debriefing and triangulation has been found to be essential to ensuring the trustworthiness of the data (Leitz, Langur, \& Furman, 2006). The data are presented in two ways. First, passages that represent the major themes in the data are presented. The authors discussed these responses in comments designed to contextualize the findings. Frequency tables are presented to help the reader understand which responses were typical of this population; the researchers recognize that any numerical presentation of qualitative data, based upon a sample such as this, should not be taken as representative of the general population.

\section{FINDINGS}

\section{Question \# 1: What Does Being a Good Father Mean to You?}

Thematic analysis revealed a set of five non-overlapping themes that describe fathers' perceptions of good fathering. The key themes were "being there," teaching, meeting the child's needs, being a role model, and offering emotional support (Table 1).

\begin{tabular}{|lcc|}
\hline Table 1: Responses to Being a Good Father & \\
\hline Responses & \# of Men Who Responded & Percentage \\
\hline Being there & 32 & 70 \\
Teaching & 23 & 50 \\
Meeting the child's needs & 17 & 37 \\
Being a role model & 13 & 28 \\
Offering emotional support & 7 & 15 \\
Paying attention to the child & 5 & 11 \\
Being supportive & 5 & 11 \\
Playing with & 4 & 9 \\
Being patient & 1 & 2 \\
\hline Total Responses 46 & & \\
\hline
\end{tabular}

The key themes listed in Table 1 are highlighted and described below.

\section{"Being there"}

Respondents believe that an important component of good fathering includes being available for their children. This was the most popular theme, appearing in 32 of the total responses and underscored by 46 participants. The importance of being accessible to their children, or simply "being there," was expressed in a variety of ways. One respondent states about his child, "I have to take care of my responsibilities, be there for him, make sure he knows I am part of his life, and will always be there." Similarly, another respondent describe "being there" for his child 
as part of taking care of his responsibilities as a man but also to "make the child feel wanted." Fathers then expressed the importance of "being there" as not only fulfilling a responsibility but also providing emotional security for their families.

\section{Teaching}

The second most popularly identified theme of being a good father was the importance of teaching the child. Fathers underscored the importance of teaching their children to be able to distinguish between "right and wrong" as well as providing them with structure. One respondent relates:

To me, it means being able to provide for her a well-structured avenue, so to speak, in terms of her growing up. Giving her some value and making sure she knows exactly what is right and wrong, and giving her a sense of purpose for her being her.

Fathers then talked about the meaning of teaching their children life-lessons that will foster strong values and self-esteem as well as enable them to become functional adults.

\section{Meeting the Child's Needs}

Fathers also identified the importance of financially meeting their child's needs. One respondent stated, "You got a responsibility to work, to have the money to buy the baby stuff, and make sure the baby has everything he needs, because that baby's special to you." Providing for the financial needs of the child is then underscored by some fathers, because it sustains the child's physical well-being.

\section{Being a Role-Model}

Fathers further discussed their key role as role models and the importance of fostering supportive relationships with their children:

First of all, that means representing a positive male role model. I came from a place where mothers can teach men how to be a better man, and fathers can teach daughters to be betters daughters. I always try to be a positive role model. I always try to show that I care about her and support her, do things for her, encourage her, play with her. Let her know she's special. I think it's important for her to have that male role model, because her biological dad is choosing not to be part of what is going on. I try to be there to support things and really connect with her, bond with her. I feel that's something she's going to need.

Fathers then relay the importance of being a good role model or a "pillar of strength" for their child despite (or maybe because of) the less than ideal social conditions that their child may be growing up in. Sometimes, the responsibility of striving to be a good role model for their child may be difficult. A respondent relays, "I was still young, so I had to start acting like a grownup, because I had a son to take care, and he has to have someone as a role model so he won't go the wrong route."

\section{Offering Emotional Support}

Fathers discuss the importance of emotionally supporting and validating their child, even if it may not conform to traditionally held ideas of masculinity: 
A lot of men probably have trouble being there emotionally when their child wants to be affectionate. I think, as he grows older, I'll have to be there for him emotionally as he develops and as he learns and changes, especially when he enters adolescence.

Fathers then identify the importance of "listening to your kids, being active with your kids, being interactive with your kids, showing concern..." as a key component of fathering.

After this general question, some men were asked more probing questions regarding their experiences of fathering. The following is how a number of men addressed some of these probing questions.

\section{Question \#2: What Are the Positive Aspects of Being a Father?}

Two themes emerged identifying a father's perceptions of the positive aspects of fatherhood (Table 2). A number of respondents $(\mathrm{N}=13)$ answered that the love and affection they give to and receive from their child are positive aspects of being a father. Three respondents stated that, as a result of being a parent, they have matured, while one respondent answered that, as a result of being a father, he has learned about life. The two key themes are discussed below.

\begin{tabular}{|lcc|}
\hline Table 2: Positive Aspects of Fathering & \\
\hline Responses & \# of Men Who Responded & Percentage \\
\hline Affection/love & 13 & 76 \\
Maturity & 3 & 17 \\
Learn about fathering & 1 & 1 \\
\hline Total Responses 17 & & \\
\hline Total responses 17/no response or not applicable 30 & \\
\hline
\end{tabular}

\section{Affection/Love}

Fathers indicated that the love and affection they receive and give to their children is a significantly positive aspect of being a father. A respondent states, "Just seeing that smile on his face mostly. Just having that person there to love; I couldn't live without him now. I couldn't imagine life without him." Fathers then describe a nurturing and loving bond with their child that gives them immense happiness. Fathers also further describe their loving bond with their child as solidifying family bonds, "It's a blessing actually; it gives me a warm, loving feeling inside-a family-being-together feeling."

\section{Maturity}

Fathers further identified becoming more mature as an important and positive aspect of becoming a father.

It changed my life a lot. Before was pregnant, I was pretty wild, running around, partying, and stuff like that. I really had to take the time to think about my responsibilities and what it takes to raise a child and how it's time consuming. You have to put him first before going out or buying clothes for myself or CDs and stuff like that. 
Becoming a father then dramatically altered the perceptions and life choices of some of the respondents, whereby they now began to place their child's needs above their own needs. Furthermore, becoming a father gave some respondents a reason to care for something, such as:

Like, at first, I didn't work. I was just out there doing really bad stuff, not caring about nothing. When he came into my life, I knew I had another responsibility to my wife and him. I got a job."

Fatherhood then instilled a sense of financial and emotional responsibility that some respondents indicated they lacked before their child was born. The procurement of a job and placing their child's needs above their own needs, as well as a dramatic shift in life-styles (from partying to becoming responsible), was then identified as a positive aspect of becoming a father.

\section{Questions \#3: What Are the Negative Aspects of Being a Father?}

Three themes were identified in the respondents' perceptions of the negative aspects of fatherhood (Table 3$)$. A majority of the respondents $(\mathrm{N}=10)$ did not associate negative experiences with fathering. Some fathers $(\mathrm{N}=5)$ indicated that fathering may limit their flexibility to "pick up and go." Only one father stated that a negative aspect of becoming a father includes working more hours.

\begin{tabular}{|lcc|}
\hline Table 3: & Positive Aspects of Fathering & \\
\hline Responses & \# of Men Who Responded & Percentage \\
\hline No negative & 10 & 63 \\
Limit activities & 5 & 31 \\
Work more & 1 & 1 \\
\hline Total Responses 16 & & \\
\hline Total responses 16/no response or not applicable 31 & \\
\hline
\end{tabular}

\section{No Negative}

The bulk of the respondents indicated that there are no negative aspects of becoming a father. A respondent succinctly states, "I don't see any downsides at all. I enjoy being a father; I don't regret it.” Their enjoyment of being a father then clearly overrides any negativity or "downsides" that may be associated with becoming a parent.

\section{Limit Activities}

Some respondents indicated that becoming a father has limited their flexibility to be able to engage in recreational activities with their partner or by themselves.

We're not able to, my wife and I, do all the things we did before we had kids. We can't just get up and go; we always have to worry about childcare if we want to go out-dancing or dinner or something.

Our respondents indicated the inability to "just pick up and go somewhere" is the primary expressed negative aspect of becoming a father. 


\section{Question \#4: How Has Fatherhood Changed You?}

The majority of the respondents $(\mathrm{N}=21)$ reported an increased sense of responsibility due to fatherhood (Table 4). Others $(\mathrm{N}=8)$ indicated that their intake of alcohol and drugs had been limited due to fatherhood. While others $(\mathrm{N}=3)$ stated that fatherhood has changed their lives by limiting their leisurely activities. One respondent indicated that fatherhood has made him more patient, and another respondent stated that fatherhood has made him grow up faster.

\begin{tabular}{|lcc|}
\hline Table 4: Fatherhood Changed Your Life & \\
\hline Responses & \# of Men Who Responded & Percentage \\
\hline Had to take on more responsibility & 21 & 72 \\
Couldn't drink or use drugs & 8 & 28 \\
Limits leisure activities & 3 & 1 \\
Made them be patient & 1 & Less than 1 \\
Made them have to grow up faster & 1 & Less than 1 \\
\hline Total Responses 29 & & \\
\hline Total response 29/no response or not applicable 18 & \\
\hline
\end{tabular}

\section{Had to Take Responsibility}

Fatherhood had an altering effect upon most of the respondents who indicated that becoming a father has instilled a sense of responsibility in them.

Knowing you have a child makes you more responsible. It makes you think before you act. I never had much of a problem getting into trouble before he was around, but certain things were a lot less important before him-job security. Nowadays, it's... actually, it's a lot of weight being responsible for a child and everything from, "Does he have enough diapers and do we have enough milk in the fridge?"

Fatherhood, then, for some respondents, instilled the importance of job security in providing for their child's needs. In addition, fatherhood also led some respondents to develop responsible decision-making, whereby "you think before you act." Irresponsible behavior, through potentially illegal activity, is then no longer seen as a positive life-choice for these respondents. For example, a respondent states, "I can't run the streets like I used to. I can't hang out all the time. Gotta be there for the little one who needs you..."

\section{Couldn't Drink or use Drugs}

Some fathers further indicated that fatherhood altered their substance usage.

I was doing drugs up until her sixth month of pregnancy-partying, gangs, and whatever. I had my son and it was an awakening. I'm in college and should be entering the cadet program in a couple of months to become a police officer.

For some respondents, the birth of their child indicated to them that substance and drug use is not viable. The birth of their child was then expressed as an "awakening" that led them to curtail their substance usage and other illegal activities. 
Another father states, "I used to play in a band and be a heavy drinker. Ever since I had my son, I drank for four months, and then I stopped drinking. It's been over two years since I've drank." Fatherhood then facilitated the curtailment of substance use for some respondents.

\section{Limits Leisure Activities}

Respondents also indicated that fatherhood has limited their activities.

I used to have a lot of time for myself. I used to be able [to do whatever I wanted] whenever I didn't have kids. No, it's kind of like everything is slowed down. I worked 40 hours a week and I used to have no problem staying over time at all. Now that I have kids, that's a definite thing I gotta do-make time for them.

Fatherhood then has shifted the focus from engaging in leisurely activities, "doing whatever," or even putting in extra time at work, to individual time, to spending time with their children. The fathers' lives are then starkly different than they used to be when they did not have children. One respondent states, "Just day to day, I get to read less (laughs), I get to do fewer things I would normally like to do."

\section{Question \#5: What Are Some of the Obstacles That Keep You From Being the Kind of Father You Want to Be?}

A majority of the respondents $(\mathrm{N}=26)$ stated that their job's time requirements are the biggest obstacle to being the kind of father they want to be (Table 5). Some respondents $(\mathrm{N}=8)$ indicated that lack of finances was an impediment to being the ideal type of father, while few reported that television or electronic games, their exwives, lack of transportation, family stability, parole/courts, and family were impediments to them being the kind of father they would like to be. The key themes were then their jobs and lack of money.

\begin{tabular}{|lcc|}
\hline Table 5: Obstacles to Being a Father & \\
\hline Responses & \# of Men Who Responded & Percentage \\
\hline Job/time & 26 & 67 \\
Money & 8 & 20 \\
Electronic games/TV & 3 & 1 \\
Ex-wife, wife/in laws & 3 & 1 \\
Nothing & 3 & 1 \\
Lack of transportation & 2 & Less than 1 \\
Family stability & 2 & Less than 1 \\
Parole/courts & 1 & Less than 1 \\
Family & 1 & Less than 1 \\
\hline Total Responses 39 & \\
\hline Total response 39/no response or not applicable 8 & \\
\hline
\end{tabular}


Job

The bulk of the respondents discussed the time-consuming nature of their employment. Some respondents talked about the long hours they worked or weekend employment, in addition to having to work two jobs.

Like I said, when I get off work, I'm usually in bed for the rest of the day; I don't really feel like going anywhere or doing anything. I'm so tired-my job.

I hate to say it, but there's times when I don't interact with her that much.

Employment then often places a physical as well as emotional strain on the father, leaving him exhausted and with little energy to interact with his child. Some fathers then expressed the desire for more time to be able to spend with their children. One respondent states, "I wish I had more time, sometimes. Keeping the ball rolling is stressful."

\section{Money}

Some fathers expressed lack of finances are an obstacle to being the kind of father they would like to be. Fathers expressed how having more money could potentially enhance their parenting.

If I could make enough money so my wife could stay home with them, that would be great. There are certain things I'd like to do with them and that stuff costs money, and right now, we don't have the extra money to do that.

Lack of finances is then perceived by some fathers as disallowing them from being involved in the type of activities they would like to be involved in with their children. One respondent states, "Money. (laughs) Finances. I'd like to be able to take them everywhere."

\section{DISCUSSION}

The results indicate that Mexican-American fathers feel that it is important to be involved in the lives of their young children. This idea of "being there" for their children is in agreement with other research on fathers (Shears et al., 2006; Allen \& Doherty, 1996). This suggests that fathers in low-income Mexican-American families have similar perceptions of being a good father as men of other racial and ethnic backgrounds. With the exception of offering emotional support, these men generally held very traditional beliefs regarding their importance to childrearing. The responses of being there, teaching, meeting the child's needs, and being a role model, all represent very traditional beliefs in fathering. This focus on traditional fathering attitudes is somewhat surprising, given the recent adoption of more contemporary attitudes of fathers.

One area where there may be a shift from more traditional to contemporary attitudes is when men talked about the positive aspects of being a father. Their responses indicated that these men were comfortable and enjoyed the affection they received from their child. This is an important finding, as men often may not be viewed as being important, affective models and providers of care in the lives of their children. Contrasted to the above noted traditional roles, Mexican-American men in this study clearly understand and value their importance to the affective lives of their children. 
When asked about negative experiences of fathering, a number of men stated there were no negative experiences. This is interesting, given that these are fathers in low-income families. However, it is certain that these men have similar ideas of good fathering as middle-income men, but generally they have fewer economic resources. One might expect that a negative experience for these men would be their difficulty in meeting their personal fathering expectations, but this was not the case. This clearly demonstrates the strength and resiliency of this population, and their recognition of the value of fathering within the context of various family constellations.

A number of men expressed that, having a child was a positive, life-changing event. Simply put, becoming a father changed their lives in a positive way. Several men stated that they stopped or greatly reduced their participation in risky behaviors, such as doing illegal drugs or participating in illegal activities. One might question whether this finding is partly the result of the low-income status of several of these fathers. It has been suggested that illegal drug and alcohol use might be equally represented across economic levels, particularly during adolescence (Schensul \& Burkholder, 2005). However, research in this area also suggests that many in middle-class communities tend to "grow out" of such risky behaviors (Arnett, 2004; Sehulenberg, O’Malley, Bachman, Wadsworth, \& Johnston, 1996). Being a father, then, may provide some inoculation against various psychosocial and behavioral maladies.

One area that may address the issues of economic status and men's perceptions of fathering is when the men were asked about the difficulty in being the kind of father they want to be. Most men responded that lack of economic resources and their working to secure these resources were significant obstacles that are impeding them from becoming the type of father they want to be.

Given that Mexican-American fathers held very similar ideas of fathering as Anglo fathers suggests the possibility of a unifying theme in highly involved fathers. These results support similar findings of other studies (Brayfield, 1995) that suggest fathering in low-income families is not very different from the role of fathering in other socioeconomic classes. Future studies might examine how fathering might differ across racial and ethnic populations, attempt to understand how mothers influence the type and frequency of fathers' involvement with their children, and explore how much fathers contribute to mothers' involvement with children.

\section{IMPLICATIONS FOR PRACTICE}

This study helps us to understand more about the fathering of young infants in self-identified Mexican-American families. Men involved in this study generally found value in both traditional male fathering roles and more contemporary affective roles. Men in this study clearly were self-reflective about their own fathering and understood the importance of their affective contributions to the lives of their children. This study confirms that Mexican-American fathers' attitudes and activities might be changing similarly to contemporary fathers across ethnic and racial groups. Although there has been an increase in fathering research studies and available literature, researchers must be cognizant that the 
process and topic under study is constantly changing. In addition, we need to be mindful that men from various economic levels and ethnic/racial groups might offer different views of their fathering roles, and we need to remain diligent to also hearing their varied voices.

There are specific implications for family and social service practice, given the increased numbers of Mexican-American families in the United States. We should be mindful that many of the families with which we work may be considered fragile families by virtue of their limited resources and/or unstable relationships. However, as this study demonstrates, fathering in and of itself may be a powerful factor in strengthening the lives and experiences of men, whether or not they are members of a traditional family constellation. Fathering itself seems to provide men with powerful experiences that increase their desires and abilities to engage in prosocial behavior. Practitioners may focus on helping fathers in traditional nuclear families and those who parent outside of these relationships to understand the powerful, positive influence fathering may have. Practitioners must seek to validate the strengths of Latino men and the many ways in which they positively contribute to the lives of their children.

Additionally, since it is clear that affective caretaking is an important component to the parenting experience of Latino men, practitioners must understand this role in the context of Latino culture. Viewing Latino men through a narrow understanding of machismo is limiting. Machismo should be viewed more as a deep sense of obligation to the family, regardless of the particular family structure. The positive aspects of Latino male fathering, which includes traditional, economic, and affective care, must be understood. Practitioners who are unfamiliar with Latino culture are encouraged to utilize a strengths-based lens through which to view the experiences of Latino men as fathers. That is, they should seek to understand the lived experiences of their clients and how their clients possibly contribute to the lives of their children. Having a clear understanding of the fathers' unique contributions to early infant development and how it is vastly different from mothering would be a good start for practitioners and child-care providers. Helping to educate parents on these issues is important, as many families may not understand the fathers' importance in child rearing. Families need to know and understand the importance of fathers to children's emotional and financial well being. In many cases, young men may not understand their own importance; educational interventions should focus on the positive relationship that fathering has both on the child and the young father.

\section{References}

Allen, W.D., \& Doherty, W.J. (1996). The responsibilities of fatherhood as perceived by African-American teenage fathers. Families in Society, 77, 142-155.

Arnett, J.J. (2004). Adolescence and emerging adulthood: A cultural approach (2 ${ }^{\text {nd }}$ ed.). Upper Saddle River: Prentice Hall.

Bader, A.P. (1995). Engrossment revisited: Fathers are still falling in love with their newborn babies. In J.L. Shapiro, M.J. Diamond, \& M. Greenberg (Eds.), Becoming a father (pp. 224-233). New York: Springer. 
Boller, K., Cabrera, N., Raikes, H., Pan, B., Bradley, R., Shears, J. \& Roggman, L. (2006). The Early Head Start father studies: Design, data collection, and summary of father presence in the lives of infants and toddlers. Parenting: Science and Practice, 6(2/3), 117-143.

Brayfield, A. (1995). Juggling jobs and kids: The impact of employment schedules on fathers caring for children. Journal of Marriage and the Family, 57, 321-332.

Bumpass, L.L., Raley, R.K., \& Sweet, J.A. (1995). The changing character of stepfamilies: Implications of cohabitation and non-marital childbearing. Demography, 32, 425-436.

Caelli, K., Ray, L., \& Mill, J. (2003). "Clear as mud”: Toward greater clarity in generic qualitative research. International Journal of Qualitative Methods, 2(2). Article 1.Retrieved [6-7-2006] from: http://www.ualberta.ca/ iiqm/backissues/pdf/caellietal.pdf.

Cherlin, A., \& Griffith, J. (1998). Methodological issues in improving data on fathers: Report of the working group on the methodology of studying fathers. Battelle Memorial Institute, prepared for the NICHD workshop, Improving Data on Male Fertility, Family Formation and Fatherhood, Urban Institute (January, 1997), Washington, D.C.

Cowan, C.P., \& Cowan, P.A. (1987). Men's involvement in parenthood: Identifying the antecedents and understanding the barriers. In P.W. Berman \& F.A. Pedersen (Eds.), Men's transitions to parenthood (pp. 145-171). Hillsdale, NJ: Erlbaum.

Federal Interagency Forum on Child and Family Statistics. (1998a). America's children: Key national indicators of well-being. Washington, D.C.: U.S. Government Printing Office.

Federal Interagency Forum on Child and Family Statistics. (1998b). Nurturing fatherhood: Improving data and research on male fertility, family formation, and fatherhood. Washington, D.C.: U.S. Government Printing Office.

Furman, R., \& Collins, K. (2005). Culturally sensitive practices and crisis management: Social constructionism as an integrative model. Journal of Police Crisis Negotiation, 5(2), 47-57.

Furman, R., \& Negi, N. (2007). Social work practice with transnational Latino populations. International Social Work, 50(1), 107-112.

Hernandez, D.J., \& Brandon, P.D. (2002). Who are fathers of today? In C.S. Tamis-LeMonda \& N. Cabrera (Eds.), Handbook of father involvement (pp.33-62). Mahwah, NJ: Erlbaum.

Hofferth, S. (2003). Race/ethnic differences in father involvement in two-parent families: Culture, context, or economy? Journal of Family Issues, 24(2), 185-216.

Horn, W.F. (1999). Did you say "movement”? In W.F. Horn, D. Blankenhorn, \& M.B. Pearlstein (Eds.). The fatherhood movement: A call to action (pp. 1-15). Lanham, MD: Lexington Books.

Housaain, Z., Fields, T.M., Pickens, J., Malphurs, J., \& Del Valle, C. (1997). Father's caregiving in low-income African-American and Hispanic American families. Early Development and Parenting, 6, 73-82.

Jarrett, R.L., Roy, K.M., \& Burton, L.M. (2002). Fathers in the "Hood": Insights from qualitative research on low-income African-American men. In C.S. Tamis-LeMonda \& N. Cabrera (Eds.), Handbook of father involvement (pp. 211-248). Mahwah, NJ: Erlbaum.

Kokkinaki, T., \& Kugiumutzakis, G. (2000). Basic aspects of vocal imitation in infant-parent interaction during the first 6 months. Journal of Reproductive and Infant Psychology, 18, 173-187.

Lamb, M.E. (1997). The role of the father in child development ( $3^{\text {rd }}$ ed.). New York: Wiley.

Lamb, M.E. (2002). Infant-father attachments and their impact on child development. In C.S. TamisLeMonda \& N. Cabrera (Eds.), Handbook of father involvement (pp. 93-118). Mahwah, NJ: Erlbaum.

Lamb, M.E., \& Lamb, J.E. (1976). The nature and importance of the father infant relationship. Family Coordinator, 25, 379-386.

Leitz, C., \& Langur,, C.L., \& Furman, R. (2006). Establishing rigor in qualitative research in social work: Implications from a study regarding spirituality. Social Work Research and Practice, 5(4), 441-458.

Mincy, R.B. (2002). What about Black fathers? The American Prospect, 13(7), 56-58.

Parke, R.D. (1995). Father and families. In M. Bornstein (Ed.), Handbook of parenting: Vol. 3. Status and social conditions of parenting (pp. 27-64). Mahwah, NJ: Erlbaum. 
Palkovitz, R. (2002). Involved fathering and child development: Advancing our understanding of good fathering. In C.S. Tamis-LeMonda \& N. Cabrera (Eds.), Handbook of father involvement (pp. 119-140). Mahwah, NJ: Erlbaum.

Sabogal, F., Marin, G., \& Otero-Sabogal, R. (1987). Hispanic familism and acculturation: What changes and what doesn't. Hispanic Journal of Behavioral Sciences, 9, 397-412.

Sagi, A. (1982). Antecedents and consequences of various degrees of paternal involvement in child rearing: The Israeli project. In M.E. Lamb (Eds.), Nontraditional families: Parenting and child development (pp. 205-228). Hillsdale, NJ: Erlbaum.

Sanchez, Y.M. (1997). Families of Mexican origin. In M.K. DeGenova (Ed.), Families in cultural context (pp. 61-83). Mountain View, CA: Mayfield.

Schensul, J.J., \& Burkholder, G.J. (2005). Vulnerability, social networks, sites, and selling as predictors of drug use among urban African American and Puerto Rican emerging adults. Journal of Drug Issues, 5(2), 379-408.

Schulenberg, J., O’Malley, P., Bachman, J., Wadsworth, K., \& Johnston, L. (1996). Getting drunk and growing up: Trajectories of frequent binge drinking during the transition to adulthood. Journal of Studies on Alcohol, 57, 121-132.

Shears, J. (2007). Fathering activities and attitudes across race and ethnicity. Journal of Early Childhood Research, 5(3), 245-261.

Shears, J., \& Robinson, J. (2005). Fathering attitudes and practices: Influences on children's development. Child Care in Practice, Volume 11, (1), 63-79.

Shears, J., Summers J., Boller, K., \& Barclay-McLaughlin, G. (2006). Exploring fathering roles in low-income families: The influence of intergenerational transmission. Families in Society, 87(2), 259-268.

Snarey, J. (1993). How fathers care for the next generation: A four-decade study. MA: Harvard University Press.

Storey, A.E., Walsh, C.J., Quinton, R.L., \& Wynne-Edwards, R.E. (2000). Hormonal correlates of paternal responsiveness in new and expectant fathers. Evolution and Human Behavior, 21, 79-95.

Tanfer K., \& Mott, F. (1997). Data and measurement issues: The meaning of fatherhood for men. Battelle Memorial Institute, prepared for NICHD workshop Improving Data on Male Fertility, Family Formation and Fatherhood, Urban Institute January, 1997), Washington, D.C.

Toth, J., \& Xu, X. (1999). Ethnic and cultural diversity in fathers' involvement: A racial/ethnic comparison of African American, Hispanic, \& White fathers. Youth and Society, 31, 76-99.

Vega, W.A. (1990). Hispanic families in the 1980s: A decade of research. Journal of Marriage and the Family, $52,1015-1024$

Yogman, M.W. (1981). Games fathers and mothers play with their infants. Infant Mental Health Journal, 2, 241-248.

\section{Author's Note:}

Address correspondence to: Jeffrey K. Shears, Ph.D., associate professor and BSW coordinator, College of Health and Human Services, Department of Social Work, 9201 University City Blvd., Charlotte, NC 28223, USA. e-mail: jkshears@ uncc.edu. 